Article

\title{
Physiological and Dry Matter Characteristics of Spring Maize in Northeast China under Drought Stress
}

\author{
Peng Jiang ${ }^{1,2,3}$, Fu Cai ${ }^{2, *}$, Zi-Qi Zhao ${ }^{2}$, Ying Meng ${ }^{3}$, Ling-Yun Gao ${ }^{3}$ and Tian-Hong Zhao ${ }^{1, *}$ \\ 1 College of Agronomy, Shenyang Agricultural University, Shenyang 110866, China; \\ jiangpenglnqx@syau.edu.cn \\ 2 Institute of Atmospheric Environment, China Meteorological Administration, Shenyang 110166, China; \\ ziqizhao@yahoo.com \\ 3 Liaoning Branch of Training School of Meteorological Cadres in China Meteorological Administration, \\ Shenyang 110166, China; mylnqx@163.com (Y.M.); chinalnqx@sina.com (L.-Y.G.) \\ * Correspondence: caifu_80@163.com (F.C.); zth1999@163.com (T.-H.Z.); Tel.: +86-024-83187017 (F.C.)
}

Received: 10 September 2018; Accepted: 31 October 2018; Published: 2 November 2018

\begin{abstract}
This paper examined impacts of drought on both physiological and dry matter characteristics of spring maize grown in Liaoning, China in 2016. We compared responses of dry matters of various parts, yield components, leaf photosynthesis, and transpiration to four drought levels: RD (no drought treatment), D1 (drought treatment between the 38th and 65th day after sowing), D2 (drought treatment between the 38th and 79th day after sowing), and D3 (drought treatment between the 53rd and 93rd day after sowing). Results indicate that the long-term drought in either jointing period or tasseling period had a severer impact on the dry matters and yield components than the short-term drought in jointing period. Moreover, the dry matters and the corresponding partitioning coefficients of different parts were distinct. The yield reduction was caused by the decreases of ear length and bald tip ratio during the short-term drought at jointing period, while it was caused by the reductions of ear length, ear diameter, and grain number per spike during the long-term drought in jointing and tasseling periods. Responses of leaf photosynthesis and transpiration to drought were lagging, but reactions of tasseling drought were faster. Leaf photosynthesis and transpiration after a short-term drought in jointing period could recover to an average level but that after the long-term drought in either jointing or tasseling period could not, after irrigation.
\end{abstract}

Keywords: dry matter; drought stress; tasseling period; jointing period; yield component; photosynthesis and transpiration

\section{Introduction}

Drought is one the most significant factors hindering agricultural development and environmental sustainability [1-4]. Maize is extremely sensitive to drought suffering $20-30 \%$ or even higher yields [5]. Northeast China with its cultivated area of six million hectares contributes significantly to food production in China [6]. Northeast China has witnessed frequent and intensified drought since 1990s. It is projected that water scarcity will be dramatically aggravated, which means impacts of drought on spring maize will be further exacerbated [7]. To accurately assess drought-induced decrease of maize production and well-informed farmers with reasonable maize production suggestions, therefore, it is essential to conduct studies on the impacts of drought on spring maize production in Northeast China. 
Drought-induced yield reduction is not only related to drought intensity but also determined by the time when drought starts and the period it lasts [8]. Many researchers have examined impacts of drought at specific growth periods on maize production [9-12]. Drought stress can suppress plant growth at the seedling period, leading to a dramatic reduction in whole plant biomass [13-15]. Drought emerging later from jointing to milk periods could make considerable differences in maize morphology and yield $[16,17]$.

Studies on maize physiological responses to drought stress are important to understand drought-induced maize reduction $[18,19]$. Various physiological processes of maize were affected by drought stresses, of which photosynthesis suffered from the most influences [20,21]. Nevertheless, limited studies have been conducted to examine responses of maize photosynthesis to drought stress. Nielsen et al. [22] found that maize photosynthesis rate increased slightly at the early period of drought stress, while the photosynthesis rate gradually declined with the prolongation of drought stress. Efeoğlu et al. [23] pointed out that moderate or severer drought stress would cause chlorophyll of maize to dysfunction, which then restricted photosynthesis of plants. Moreover, when maize suffered from severe drought, photosynthetic capacities of the tasseling period would decrease dramatically, which were worse than those in both milk and jointing periods.

Furthermore, the crop yield is determined by dry matter (DM) accumulation. Specifically, DM partitioning coefficients (DMPC) of root, stem, and leaf are generally used to represent proportions of photosynthetic products transported to these organs. However, drought can affect partitioning coefficients and accumulations of photosynthetic products in different organs, and finally crop yield [23]. Under drought stress, more photosynthetic products will be transported to root systems for water absorption, resulting in a larger root DMPC. Nevertheless, existing plant models have only presented values of DMPCs of distinct parts at distinct periods, without consideration of environmental conditions. Therefore, it needs further studies to assess DMPCs under different degrees of drought stress [24].

Therefore, the overall goal is to investigate drought and its impacts on physiology and DMs of spring maize. In specific, the objectives of this study are to: (1) examine the responses of biomass production and DMPCs of entire plant, leaf, stalk, ear, and root to different drought severity; (2) investigate the impacts of drought on yield and yield components; and (3) understand the variations of physiological functions under drought. Overall, this study can help researchers and farmers with better understandings of physiological responses of maize to drought stress and physiological performances after irrigation.

\section{Materials and Methods}

\subsection{Experimental Scheme}

The experiment was carried out in a drought prone testing site of Jinzhou Agricultural Meteorological Experiment Station $\left(41^{\circ} 49^{\prime} \mathrm{N}, 121^{\circ} 12^{\prime} \mathrm{E}\right.$, altitude: $\left.17 \mathrm{~m}\right)$, Liaoning Province, China in 2016. There were 12 testing blocks with the dimensions of $5 \mathrm{~m} \times 3 \mathrm{~m}$ in this experiment. Each block was separated by cement layer to avoid water infiltration. Meanwhile, mobile canopies were used to shelter blocks from natural precipitation, so that different levels of drought stress could be realized via controlling water and irrigation artificially. 
The spring maize with the variety name of Dayu 406, was sowed on 23 May 2016, where row spaces were set as $40 \mathrm{~cm} \times 60 \mathrm{~cm}$. Compared with a reference scenario (RD) with enough water supply, three levels of drought stress (D1, D2, and D3) were artificially simulated, with each scenario occupying three plots, respectively. The group of RD was irrigated every seven days with a water amount of $10 \mathrm{~mm}$ between third leaf and jointing while irrigating pattern changed every seven days with water amounts of $25 \mathrm{~mm}$ from jointing to milk, and every seven days with $10 \mathrm{~mm}$ between milk and maturity. Specific time durations corresponding to growth periods are illustrated in Figure 1. For the drought treatments (as shown in Figure 1), D1 was controlled between the 38th and 65th day, covering the early jointing, tasseling, flowering, and early silking periods. D2 was controlled between the 38th and 79th day, covering the early jointing, tasseling, flowering, and middle silking periods. The water supply of D3 was controlled between the 53rd and 93rd day, covering tasseling, flowering, and late silking periods. Watering pattern of all cases is the same with that of RD in the remaining time.

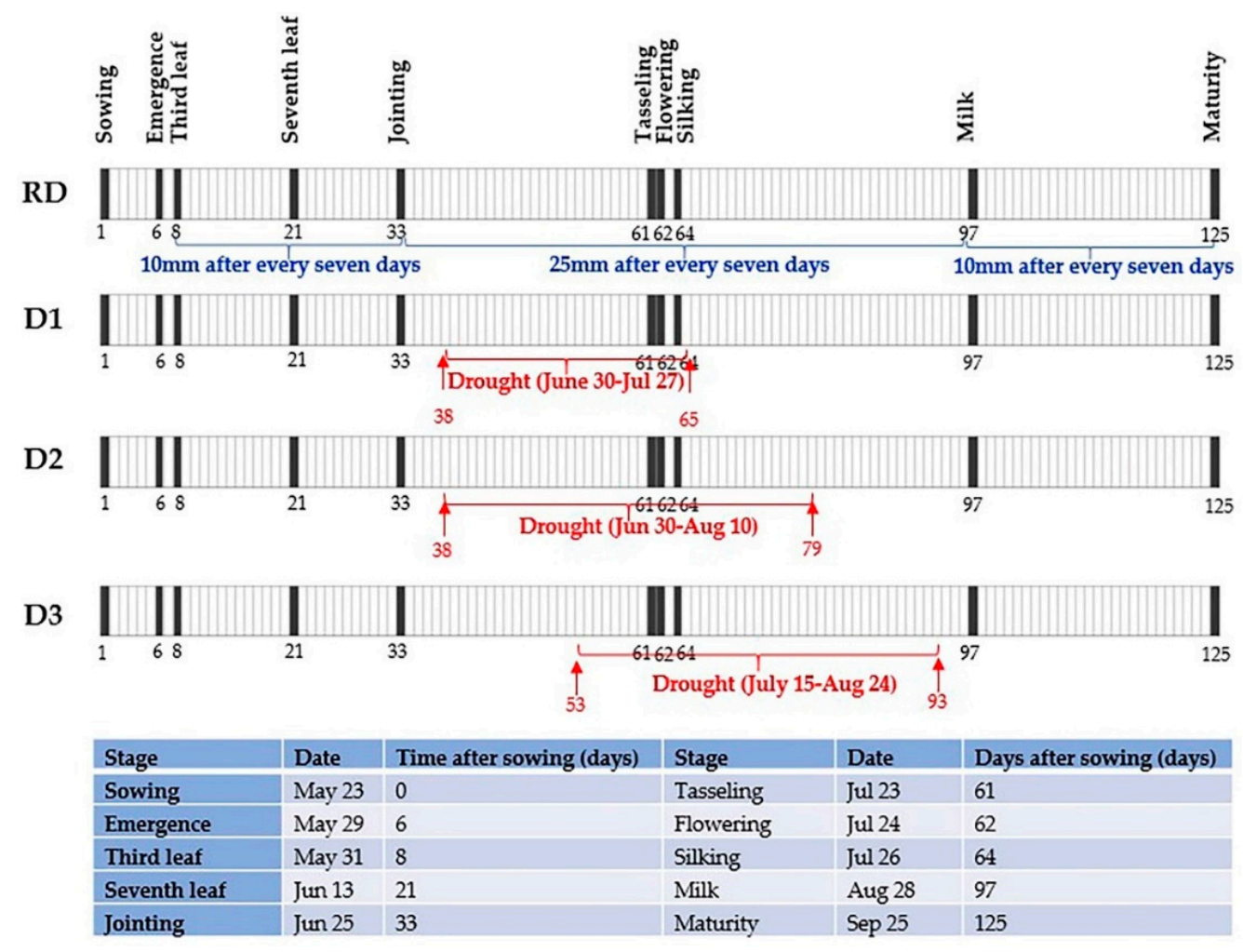

Figure 1. Critical points of growth and drought treatments of spring maize of Northeast China.

We further measured the gravimetric water content (\%) of soils at the depth of $10 \mathrm{~cm}, 20 \mathrm{~cm}, 30 \mathrm{~cm}$, $40 \mathrm{~cm}$, and $50 \mathrm{~cm}$ every five to eight days between 1 July and 26 August. The measured gravimetric soil water contents were further converted into soil relative extractable water $\theta_{r}$ based on Equation (1) [25].

$$
\theta_{r}=\frac{\theta_{m}-\theta_{w p}}{\theta_{f c}-\theta_{m p}}
$$

where $\theta_{m}$ represents the gravimetric soil water contents (\%) at the depth of $10 \mathrm{~cm}, 20 \mathrm{~cm}, 30 \mathrm{~cm}, 40 \mathrm{~cm}$, and $50 \mathrm{~cm} ; \theta_{w p}$ means the gravimetric soil water contents (\%) at wilting point, and $\theta_{f c}$ is the gravimetric soil water contents (\%) at field capacity. The variations of the soil relative extractable water $\theta_{r}$ are shown in Figure 2. Overall, the $\theta_{r}$ decreased during water-control period and increased after irrigation. The $\theta_{r}$ of all treatments were higher than 0.4 during the measurement period except for the D3. 


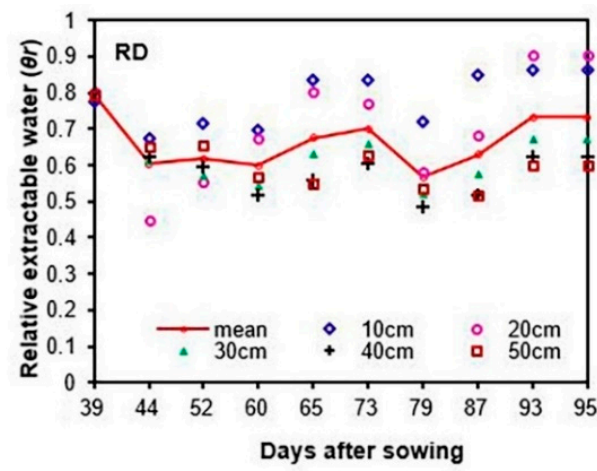

(a)

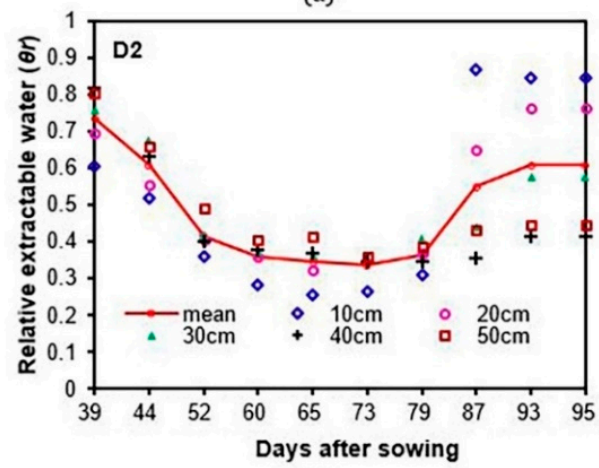

(c)

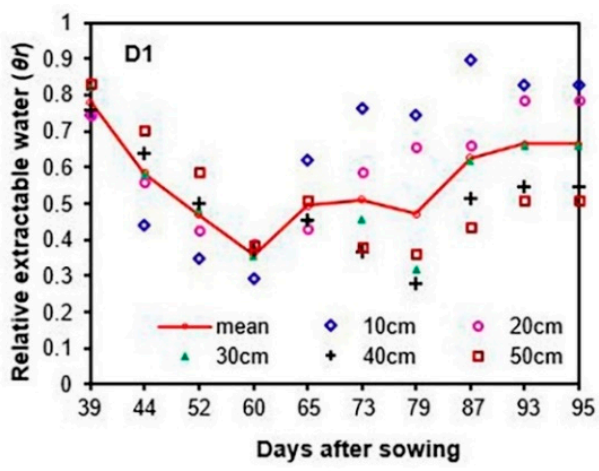

(b)

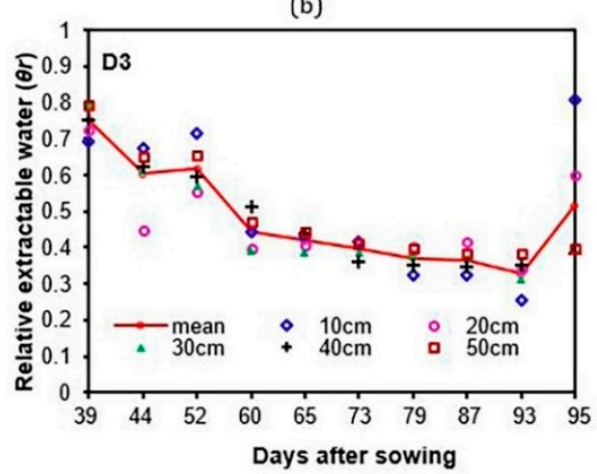

(d)

Figure 2. Variations of soil relative extractable water $\theta_{r}$ under different drought scenarios. (a) RD (no drought), (b) D1 (drought between June 30-July 27), (c) D2 (drought between June 30-August 10), and (d) D3 (drought between July 15-August 24).

\subsection{Treatments and Measurements}

Comprehensive measurements were conducted, in which DM, yield component, photosynthesis and SFR (sap flow rate) were examined. Transpiration rate $\left(\mathrm{T}_{\mathrm{r}}\right)$ over leaves were monitored with a fixed light intensity of $1500 \mu \mathrm{mol} \cdot \mathrm{m}^{-2} \cdot \mathrm{s}^{-1}$ at 9:00-11:00 a.m. Measured leaves were top-side fully-expanded-leaves and ear-leaves before and after the tasseling period. The SFR was measured with Dynagage Flow32 Sap Flow system and Dynagage sensors that could calculate the energy taken away by plant transpiration based on the principle of energy balance. The Dynagage sensors were installed at the second stalk above the ground, where leaf sheaths were ripped and treatments like water-proofing and shading were made before testing. The SFR was recorded automatically every $30 \mathrm{~min}$, after which the daily SFR could be calculated according to the SFR accumulation in a day. Net photosynthetic rate $\left(\mathrm{P}_{\mathrm{n}}\right)$ was measured by LI-6400 Portable Photosynthesis System on the 7th, 14th, and 20th day after water control, as well as the 7th, 14th, and 20th day after irrigation.

The DMs of different parts were observed every 14 days in dry weight and fresh weight. To obtain the dry weight, all samples were heated in oven at the temperature of $105^{\circ} \mathrm{C}$ for $30 \mathrm{~min}$ and weighed at ambient temperature.

For the DMPC, it is expressed by Equation (2):

$$
\mathrm{DMPC}_{i}=\frac{m_{i}}{\sum m_{i}}
$$

where $i$ represents the different parts of maize, such as leaf, ear, stalk, and root; $m_{i}$ is the dry matter of a specific part, $\mathrm{g} ; \sum m_{i}$ is the total dry weight of all parts.

In addition, plant height, stalk diameter, leaf number, and leaf age were recorded every seven days. Biomass (i.e., dry weight and fresh weight) of various organs such as stalk, root, ear, and leaf were also measured every 14 days. After harvesting, 12 plants in each group were chosen to examine ear length, ear diameter, ear weight, 100-kernel mass, and predicted yield. 


\subsection{Statistical Analysis}

The means of DMs, DMPCs, and yield components were separated by the least significant difference (LSD) test at the significance level of 0.05 [26]. These were performed on the platform of SPSS 13.0 [27]

\section{Results}

\subsection{Variations of Dry Matters}

Figure 3 presents biomass accumulation under different scenarios of drought stress. Overall, DMs of all parts in RD treatment were higher than that in other treatments. When maize underwent the same drought stress (before the 66th day in D1 and D2 cases), the DMs of all parts would be similar. For the drought in early jointing period, it almost generated no impact on the biomass production. After the 66th day, DMs of entire plant, leaf, stalk, and root in D1 case were higher than that in D2. For D3, subjected to drought effects from the 53rd day, its biomass production started to be lower than that in RD. In general, this indicates drought stress slowed down the biomass production and a longer drought duration led to larger reduction in DMs.

In specific, by comparing the maize biomass accumulation in D1, D2, and D3, it is observed that biomass in D3 case was higher than that in D1 and D2 before the 87th day. However, the biomass in D3 was finally lower than that in D1 and just slightly higher than that in D3. This is in close relationship to the different drought patterns in these three scenarios. Although maize suffered from progressive drought after the 53rd day in D3, the biomass kept increasing until the 80th day. In D1 and D2, the biomass could not increase immediately after irrigation, but exhibited a trend of decrease. Based on these, it is found that drought in jointing period exerted slight impacts on biomass production. At the same time, biomass production followed its inherent pattern and responded slowly to the drought or irrigation. From D2, it is also found that the impact of drought after silking period was significant and the biomass production could not recover.

After the 66th day, the $\mathrm{DM}_{\text {leaf }}$ witnessed the trend of progressive decline in D1, D2 and D3 cases (Figure 3b). After irrigation, $\mathrm{DM}_{\text {leaf }}$ in D1 and D2 could not recover immediately until several days later. Therefore, drought in jointing period has a significant impact on leaves, whose biomass can hardly recover after irrigation. $\mathrm{DM}_{\text {stalk }}$ was subjected to a weaker impact of drought when comparing to $\mathrm{DM}_{\text {leaf }}$ (Figure 3c). DM $\mathrm{M}_{\text {stalks }}$ of D1 and D2 were generally the same regardless of irrigation. Meanwhile, $\mathrm{DM}_{\text {stalk }}$ of D3 had not been influenced by early drought stress until the 80th day. Therefore, drought exerted a direct impact on biomass production of before flowering, after which drought made minor difference to stalk growth. Drought from tasseling to milk periods had significant impacts on ear growth. In D2 and D3, DM ears were only about $60 \mathrm{~g}$, far less than that in RD (Figure 3d). In D1, the $\mathrm{DM}_{\text {ear }}$ was same with that of D2 and lower than D3 before middle-silking but started to recover after two-week's irrigation and eventually much higher than that in D2 and D3. This indicates impacts of drought on ear growth occurred in tasseling, flowering and silking periods. DM roots of D1 and $\mathrm{D} 2$ were smaller than that of $\mathrm{RD}$ (Figure 3e). $\mathrm{DM}_{\text {root }}$ in $\mathrm{RD}$ reached its peak value at the 66th day in the tasseling period, while the $\mathrm{DM}_{\text {root }}$ of D3 started to decrease at the 73rd day. The $\mathrm{DM}_{\text {root }}$ in D1 could reach a peak value approximate to that in RD, but three weeks later than that in RD. In addition, $\mathrm{DM}_{\text {root }}$ in $\mathrm{D} 2$ reached its peak value at the 80th day. Overall, the root growth was delayed by drought, but root could eventually recover to the normal level after long-term irrigation. 


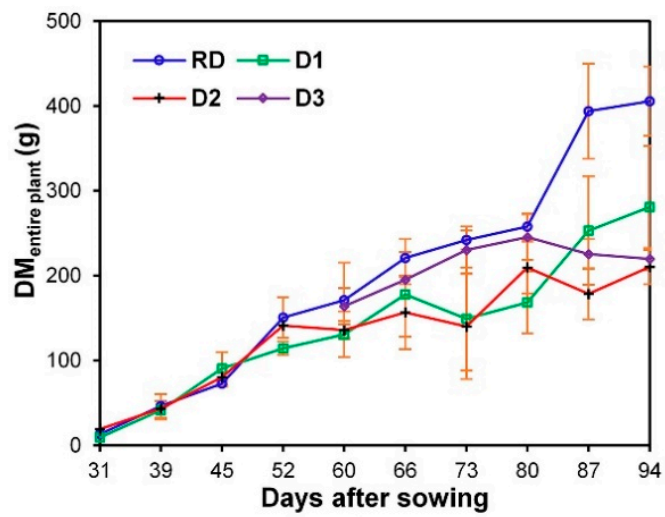

(a)

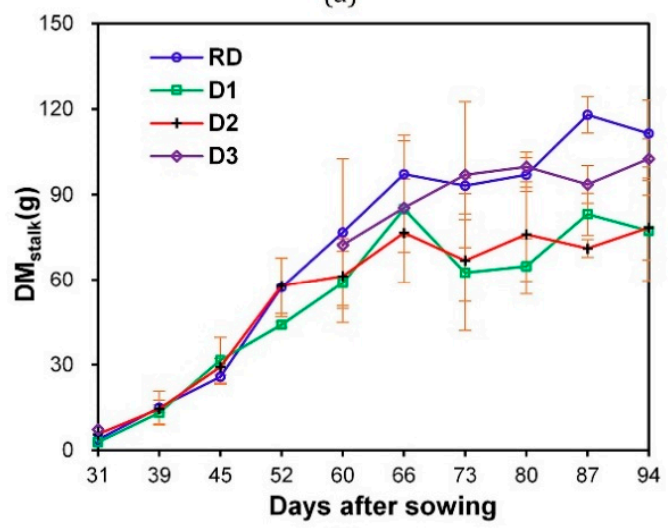

(c)

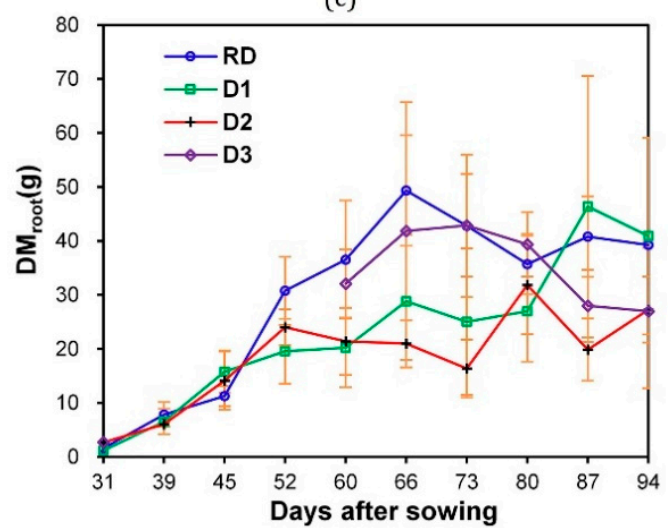

(e)

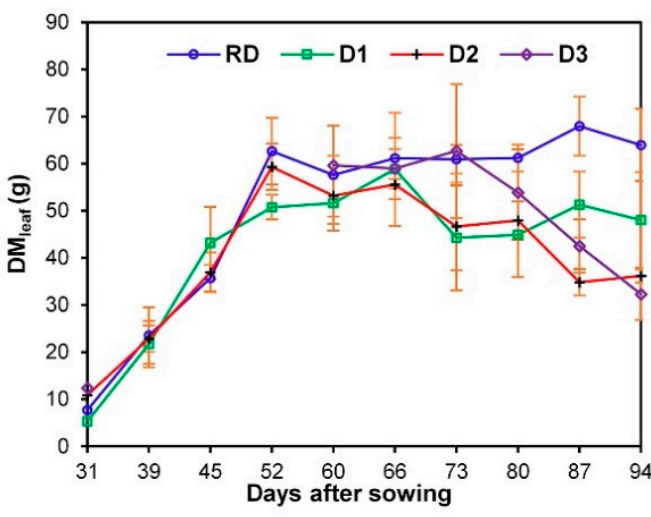

(b)

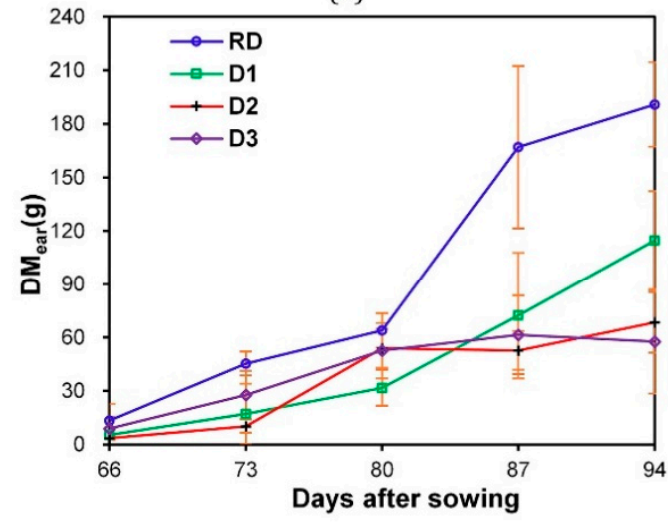

(d)

Figure 3. Impacts of drought stress on dry matters of various parts (a) entire plant, (b) leaf, (c) stalk, (d) ear, and (e) root.

\subsection{Variations of Dry Matter Partitioning Coefficients}

Drought does not only affect the DMs of different parts but also influences their partitioning coefficients, as shown in Figure 4.

$\mathrm{DMPC}_{\text {leaf }}$ followed a pattern of decrease and the $\mathrm{DMPC}_{\text {leaf }}$ was in the order of D2 $>\mathrm{D} 1>\mathrm{D} 3>$ $\mathrm{RD}$ between tasseling and milk periods, indicating that drought made more photosynthetic products allocate to leaves. Before tasseling, there was almost no difference among all $\mathrm{DMPC}_{\text {stalk }}$. After silking, the $\mathrm{DMPC}_{\text {stalk }}$ of D1 and D2 were larger, while that of D1 and D3 witnessed decreasing and increasing trends, respectively. Finally, the DMPC stalk values of D1 and RD were equal, DMPC $_{\text {stalk }}$ of D3 kept increasing and that of D2 remained at a prominent level after irrigation. This suggests severer drought led to larger $\mathrm{DMPC}_{\text {stalk }}$. 
The eventual $\mathrm{DMPC}_{\text {ear }}$ followed the trend of RD $>$ D1 $>$ D2 $>$ D3 on the 94th day, as shown in Figure 4c. For DMPC root (Figure 4d), they followed the trend of RD $>$ D3 $>$ D1 > D2 on the 66th day, meaning that $\mathrm{DMPC}_{\text {root }}$ decreased as the aggravation of drought stresses. From the 80th to 94th day, $\mathrm{DMPC}_{\text {root }}$ in RD case was smaller than that in three other drought treatments, while DMPC root in $\mathrm{D} 1$ was more substantial. Moreover, $\mathrm{DMPC}_{\text {root }}$ reached its maximum value in silking period under normal situations, while drought shifted maximum $\mathrm{DMPC}_{\text {root }}$ to an earlier date.

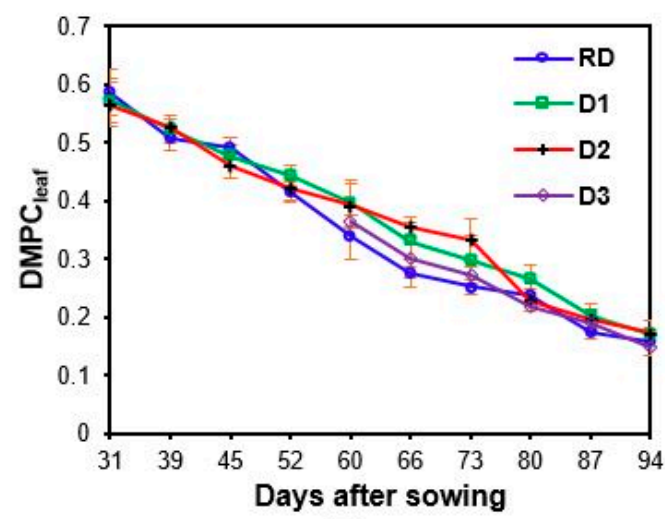

(a)

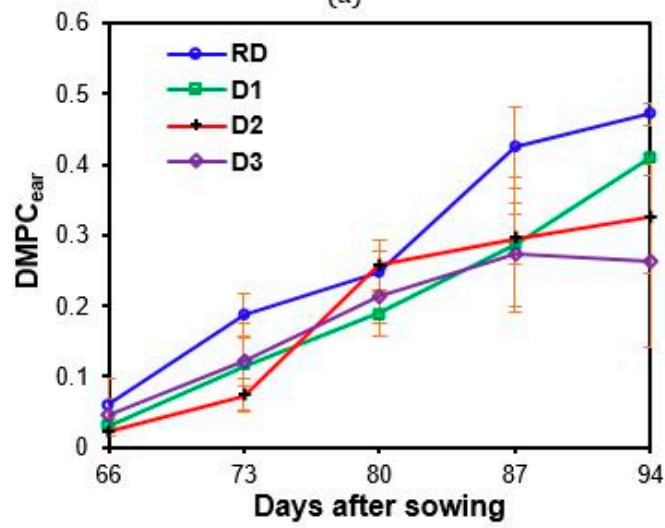

(c)

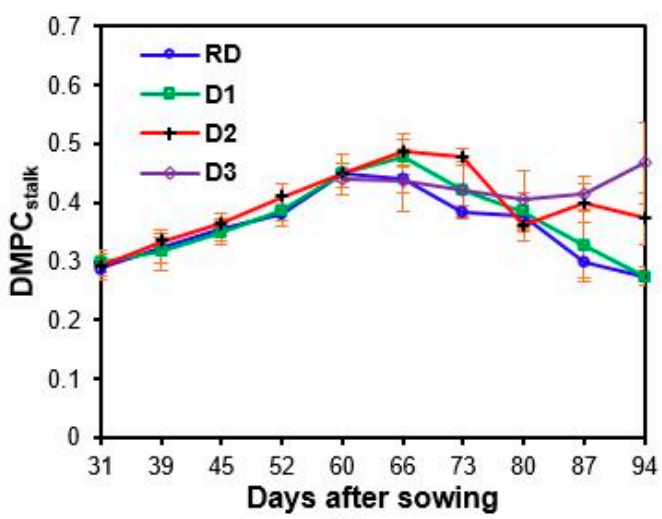

(b)

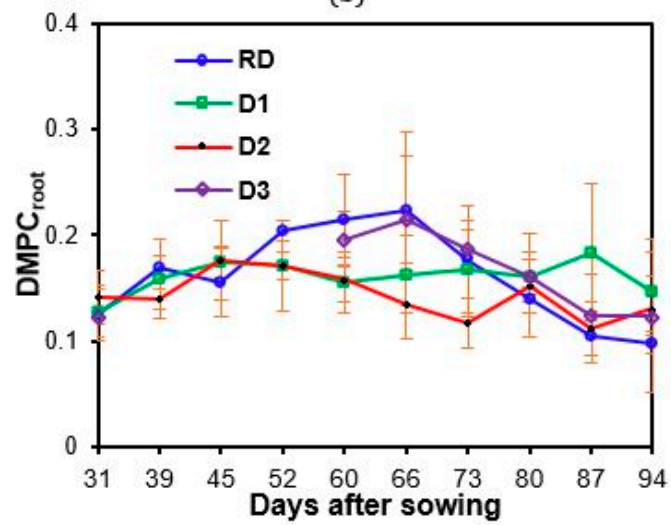

(d)

Figure 4. Responses of DM partitioning coefficients to drought stress (a) leaf, (b) stalk, (c) ear, and (d) root.

\subsection{Yield Components}

The yield components in RD, D1, D3, and D2 generally followed the pattern of decrease with the severity of drought (Table 1). Maize in D1 underwent a short-term drought, so that the maize ear length and ear diameter were smaller than that in RD. Comparatively, maize in D2 experienced long-term drought from jointing period, hence the ear length and ear diameter were significantly lower than those in other treatments. Drought durations in D2 and D3 were 40 days, so that the ear diameter was somewhat the same, but still slenderer than that of RD and D1. However, drought in D3 was later than that in D2 and ear length of D3 was less influenced, longer than that of D2.

The 100-kernel mass decreased with the pattern of RD, D1, D2, and D3, indicating that grain size decreased along drought duration. Although 100-kernel of D2 was larger than that of D3, D2 grain number per spike was less, resulting in a smaller grain mass per plant. Furthermore, yield reduction rate was calculated based on grain mass per plant. Compared with RD, D1 witnessed a relatively weaker yield reduction of $26 \%$, while both D1 and D3 underwent severer yield reductions of $54 \%$ and $47 \%$, respectively. 
Table 1. Yield component of maize under different drought stress.

\begin{tabular}{ccccccc}
\hline $\begin{array}{c}\text { Drought } \\
\text { Treatments }\end{array}$ & $\begin{array}{c}\text { Ear Length } \\
\mathbf{( c m )}\end{array}$ & $\begin{array}{c}\text { Ear Diameter } \\
\mathbf{( c m )}\end{array}$ & $\begin{array}{c}\text { 100 Kernel } \\
\text { Mass } \mathbf{( g )}\end{array}$ & $\begin{array}{c}\text { Grain } \\
\text { Number/Spike }\end{array}$ & $\begin{array}{c}\text { Grain } \\
\text { Mass/Plant (g) }\end{array}$ & $\begin{array}{c}\text { Yield } \\
\text { Reduction (\%) }\end{array}$ \\
\hline RD & $20.8 \pm 1.8^{\mathrm{a}}$ & $5.6 \pm 0.3^{\mathrm{a}}$ & $35.7 \pm 0.9^{\mathrm{a}}$ & $744.4 \pm 102.8^{\mathrm{a}}$ & $247.9 \pm 18.6^{\mathrm{a}}$ & - \\
$\mathrm{D} 1$ & $18.0 \pm 1.6^{\mathrm{b}}$ & $5.4 \pm 0.5^{\mathrm{a}}$ & $31.2 \pm 1.3^{\mathrm{a}, \mathrm{b}}$ & $595.0 \pm 102.5^{\mathrm{b}}$ & $182.4 \pm 17.5^{\mathrm{b}}$ & 26 \\
$\mathrm{D} 2$ & $13.9 \pm 1.3^{\mathrm{c}}$ & $4.7 \pm 0.2^{\mathrm{b}}$ & $28.5 \pm 0.8^{\mathrm{b}}$ & $427.1 \pm 65.9^{\mathrm{c}}$ & $113.4 \pm 12.8^{\mathrm{c}}$ & 54 \\
D3 & $17.7 \pm 1.4^{\mathrm{b}}$ & $4.8^{\mathrm{b}} \pm 0.3^{\mathrm{b}}$ & $28.1 \pm 1.2^{\mathrm{b}}$ & $492.0 \pm 49.8^{\mathrm{c}}$ & $131.3 \pm 26.3^{\mathrm{c}}$ & 47 \\
\hline
\end{tabular}

Note: Letters in columns (small letters: ${ }^{a, b, c}$ ) show differences between application rates (Mean \pm SD). Mean differences were tested at the significance level of $p<0.05$ [28].

\subsection{Maize Photosynthesis $P_{n}$}

Table 2 presents variations of $\mathrm{P}_{\mathrm{n}}$ (unit: $\mu \mathrm{mol}\left(\mathrm{CO}_{2}\right) \mathrm{m}^{-2} \cdot \mathrm{s}^{-1}$ ) and $\mathrm{T}_{\mathrm{r}}\left(\right.$ unit: $\mathrm{mmol}\left(\mathrm{H}_{2} \mathrm{O}\right) \mathrm{m}^{-2} \cdot \mathrm{s}^{-1}$ ) along time duration. On the 57th day, no significant differences could be found between $\mathrm{P}_{\mathrm{n}}$ in D2 and RD. Along drought time extension, $\mathrm{P}_{\mathrm{n}}$ in D2 declined sharply, about half of that in RD. The 66th day was a cloudy day when there was no evident difference for $\mathrm{P}_{\mathrm{ns}}$ among D1, D2, and RD. $\mathrm{P}_{\mathrm{n}}$ in D2 further reduced to 14.22 on the 72nd day, while $P_{n}$ in D1 was slightly higher because of irrigation from the 66th day. On the 79th day, $P_{n}$ in D2 dropped to its minimum value, because $P_{n}$ value started to rise after irrigation (as indicated by 22.45 on the 86th day in Table 2) but could not reach the normal value of 32.44 in RD case. Afterwards, $P_{n}$ decreased as maize was close to maturity. Although $\mathrm{P}_{\mathrm{n}}$ in D3 was higher than that in D2 on the 79th day, it decreased rapidly because of the drought.

Table 2. Responses of $P_{n}$ and $T_{r}$ to drought stress.

\begin{tabular}{|c|c|c|c|c|c|c|c|c|c|}
\hline & $\begin{array}{l}\text { after } \\
\text { ing }\end{array}$ & 57 & 65 & 66 & 72 & 79 & 86 & 93 & 101 \\
\hline \multirow{4}{*}{$P_{n}$} & RD & $29.7 \pm 4.3^{\mathrm{a}}$ & $37.0 \pm 2.4^{\mathrm{a}}$ & $18.4 \pm 5.3^{a}$ & $30.2 \pm 3.3^{a}$ & $31.5 \pm 2.7^{a}$ & $32.4 \pm 2.8^{a}$ & $27.4 \pm 3.3^{a}$ & $18.8 \pm 2.8^{a}$ \\
\hline & D1 & - & - & $19.4 \pm 3.7^{\mathrm{a}}$ & $16.3 \pm 5.7^{b}$ & - & $21.5 \pm 6.2^{b}$ & $23.8 \pm 4.6^{\mathrm{a}, \mathrm{c}}$ & - \\
\hline & D2 & $28.3 \pm 1.7^{\mathrm{a}}$ & $18.8 \pm 7.6^{b}$ & $19.5 \pm 2.6^{\mathrm{a}}$ & $14.2 \pm 8.4^{b}$ & $7.5 \pm 2.2^{b}$ & $22.5 \pm 5.9^{b}$ & $13.2 \pm 3.5^{\mathrm{b}, \mathrm{d}}$ & $12.6 \pm 2.7^{b}$ \\
\hline & D3 & - & - & - & - & $22.5 \pm 4.6^{c}$ & $16.2 \pm 6.1^{c}$ & $10.8 \pm 2.8^{b}$ & $10.4 \pm 0.7^{b}$ \\
\hline \multirow{4}{*}{$\mathrm{T}_{\mathrm{r}}$} & $\mathrm{RD}$ & $2.4 \pm 0.7^{\mathrm{a}}$ & $5.3 \pm 0.8^{a}$ & $1.7 \pm 0.6^{\mathrm{a}}$ & $4.3 \pm 1.5^{\mathrm{a}}$ & $2.9 \pm 1.2^{\mathrm{a}}$ & $2.1 \pm 0.2^{\mathrm{a}, \mathrm{b}}$ & $2.1 \pm 0.5^{a, c}$ & $0.7 \pm 0.4^{\mathrm{a}}$ \\
\hline & D1 & - & - & $1.9 \pm 0.4^{\mathrm{a}}$ & $2.0 \pm 0.9^{b}$ & - & $2.2 \pm 1.1^{b}$ & $2.6 \pm 0.6^{c}$ & - \\
\hline & D2 & $2.7 \pm 0.3^{a}$ & $2.5 \pm 1.0^{\mathrm{b}}$ & $1.8 \pm 0.3^{\mathrm{a}}$ & $2.5 \pm 1.7^{\mathrm{b}}$ & $0.2 \pm 0.1^{\mathrm{b}}$ & $2.1 \pm 0.4^{\mathrm{a}, \mathrm{b}}$ & $1.1 \pm 0.4^{b}$ & $0.5 \pm 0.2^{b}$ \\
\hline & D3 & - & - & - & - & $2.2 \pm 0.6^{c}$ & $1.5 \pm 0.9^{c}$ & $1.5 \pm 0.9^{\mathrm{a}, \mathrm{b}}$ & $0.5 \pm 0.3^{\mathrm{a}, \mathrm{b}}$ \\
\hline
\end{tabular}

Note: Letters in columns (small letters) show differences between application rates (Mean \pm SD). Mean differences were tested at the level of $p<0.05$ [28].

For $\mathrm{T}_{\mathrm{r}}$, from the 65th to 72nd day, its value in $\mathrm{D} 2$ was obviously smaller than that in RD. The value further dropped to its minimum value on the 79th day, but it rose rapidly after irrigation to 2.093 on 86th day, slightly higher than that of RD. $\mathrm{T}_{\mathrm{r}}$ of $\mathrm{D} 3$ reduced because of drought stress and did not recover after irrigation on the 93 rd day.

\subsection{Sap Flow Rate}

The SFR in RD was generally higher than that in other scenarios, with its maximum value of $300 \mathrm{~g} \cdot \mathrm{h}^{-1}$ during the tasseling period, as shown in Figure $5 \mathrm{~b}$. 


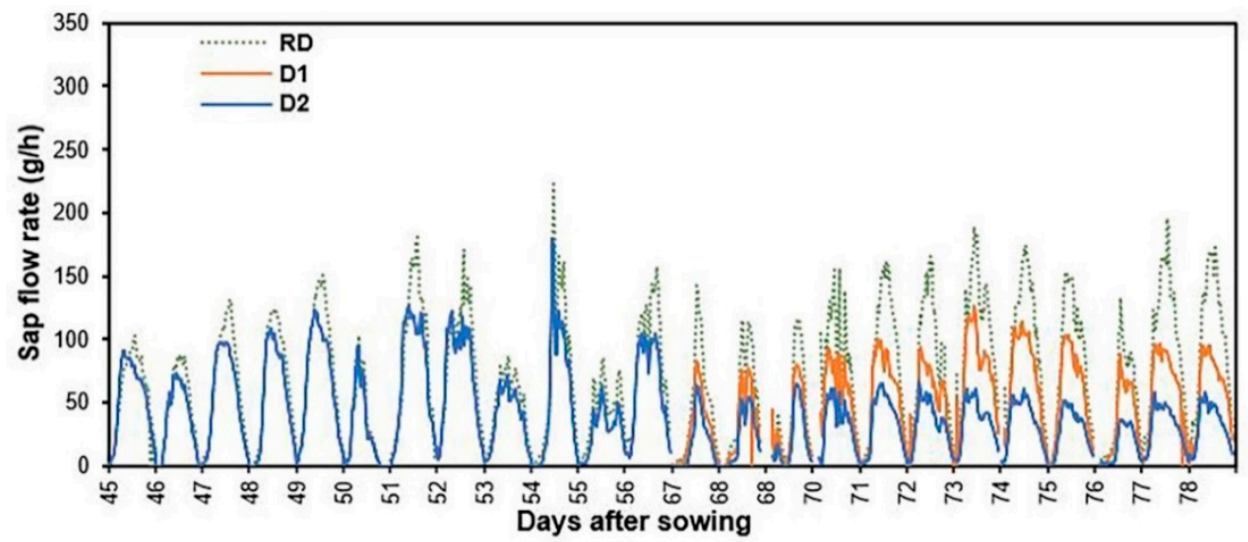

(a)

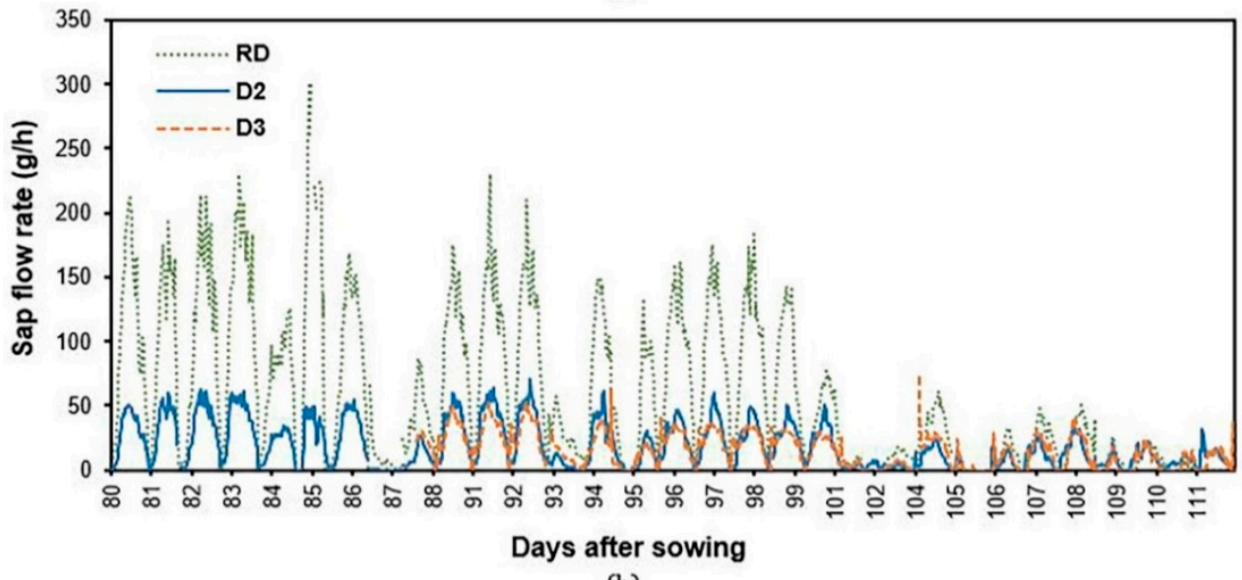

(b)

Figure 5. Variations of maize sap flow rates under different drought stress. (a) Period: between the 45th and 79th day, and (b) between the 80th and 110th day.

After irrigation from the 66th day, the daily SFR in D1 was two times higher than that in D2. However, the daily SFR in D1 could not recover to the level in RD. In D2, there was no obvious variation in the SFR before and after irrigation. This means SFR in D2 could not recover from long-term drought stress. The SFR in D3 kept decreasing regardless of the irrigation on the 94th day, illustrating that water absorption capability of root had not recovered. Relationships between daily SFR and active photosynthetic radiation were investigated, as shown in Figure 6. The relationship was exponential under the condition of normal water supply. Under drought (Figure 6a), the relationship in D1 turned to be linear $\left(R^{2}=0.8823\right)$. The relationships in $\mathrm{D} 2$ also followed the linear pattern but had a lower significance compared with that in D1 $\left(R^{2}=0.6043\right)$. Moreover, the linear relationships in D3 were less significant $\left(R^{2}=0.0048\right)$, meaning that drought stress exerted an intensified effect on SFR. In addition, the decrease in slopes in linear relationships from D1 to D3 also exhibited the impact of drought intensified.

After irrigation, the exponential relationship in D1 recovered, as shown in Figure 6b, while their curve located below that in RD. The linear relationship in D1 recovered to be exponential after irrigation but with lower SFR values (Figure 6d). The exponential relationship recovered in D3 after irrigation also recovered, as shown in Figure 6f. 

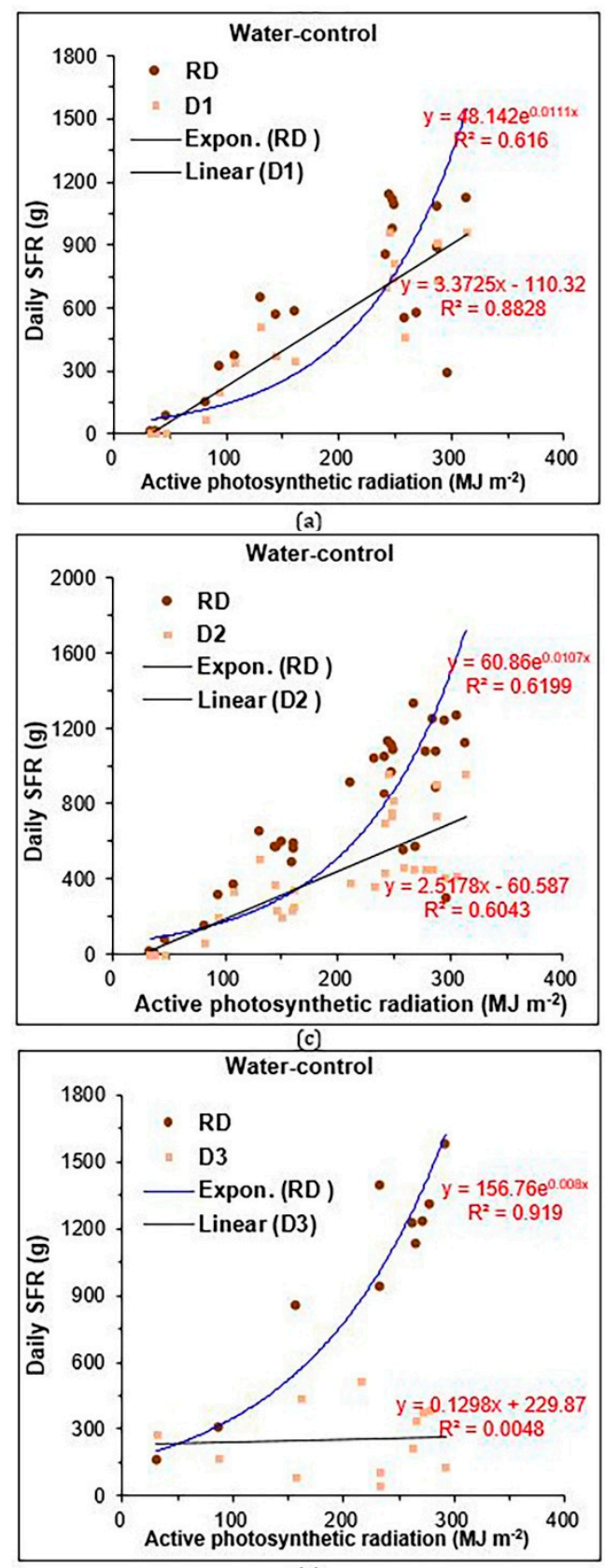

(e)
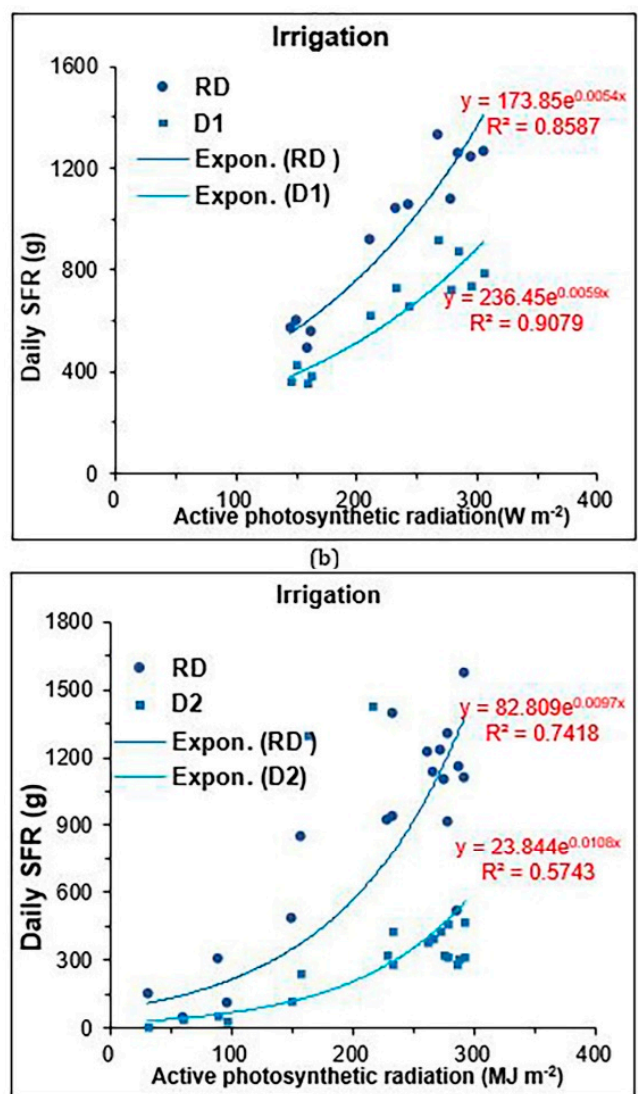

(d)

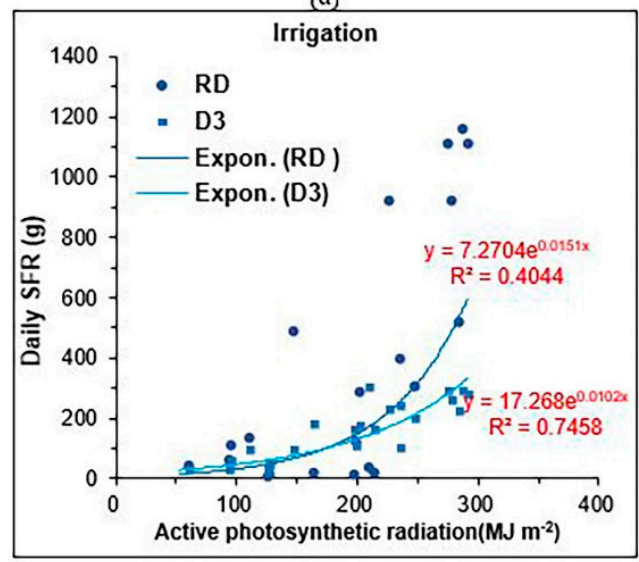

(f)

Figure 6. Comparisons of relationships between daily SFR (sap flow rate) and active photosynthetic radiation before and after irrigation. (a) RD and D1 during water-control; (b) RD and D1 after irrigation; (c) RD and D2 during water-control; (d) RD and D2 after irrigation; (e) RD and D3 during water-control; (f) RD and D3 after irrigation.

\section{Discussion and Conclusions}

Maize has been a significant cereal of many nations, playing important roles in food security. However, its yield is affected by the current global change, especially the temperature increase and the frequent drought disasters. This affirms the values to investigate the physiological and dry matter characteristics of maize under drought stress. The current study indicated that impacts of drought in tasseling period on stalk growth occurred in late reproductive period, which was consistent with leaves' responses [29]. After irrigation, leaves and stalks could not respond immediately, related to the hysteresis of early drought accumulative effects. This further indicated that early drought had a severe influence on them $[11,30]$. 
Drought in jointing period exerted obvious effects on root growth, namely longer drought was corresponding to lower recovery capabilities. Drought in tasseling period could lead to a rapid decrease of $\mathrm{DM}_{\text {root }}$ in late reproductive period, which had been evidenced in previous studies [31]. Responses of $\mathrm{DM}_{\text {ear }}$ to drought were more significantly. In specific, long-term drought from jointing to silking periods caused dramatic reductions in $\mathrm{DM}_{\mathrm{ear}}$, compared to the slight reduction under short-term

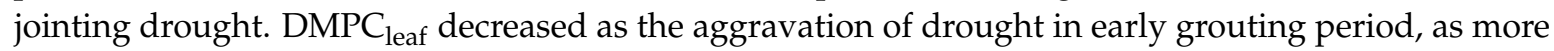
DMs were transported to leaves to guarantee the photosynthate production in reproductive period [32]. $\mathrm{DMPC}_{\text {root }}$ increased with the aggravation of drought in late grouting period, possibly because the drought had suppressed DM transportation from roots to ears [33].

Drought in jointing period caused slight influences on ear length, ear diameter, and 100-kernel mass. Grain number per spike and grain mass per plant decreased significantly, which was the primary reason of maize reduction [34,35]. Long-term drought from both jointing and tasseling periods could make differences to yield components, in which ear length, ear diameter, 100-kernel mass and grain number per plant were affected at various degrees [36]. The long-term drought in jointing period led to yield reduction through affecting ear length and effective grain number. Under drought in tasseling period, although ear length was longer, the lighter 100-kernal mass should be responsible for the yield reduction [36].

In addition, $\mathrm{P}_{\mathrm{n}}$ could not recover to a normal level after irrigation and it did not respond immediately although water supply of maize was controlled, which was in relation to the delayed leaf expansions and recoverable growth of leaves [37]. With the extension of drought period, the delayed responses to drought diminished, meaning resistant capabilities of maize photosynthesis to drought weakened. This was because photosynthetic production of leaves was mostly transported after entering reproductive period, when water consumption capacity was notably greater than that of jointing period [38]. Irrigation after short-term drought stress made $P_{n}$ increase fast and then exceeded the normal level because of compensatory effects $[39,40]$. Recovery capability of $P_{n}$ under tasseling drought was weaker than that under jointing drought, indicating the compensatory effects in the jointing drought were much stronger. Responses of $T_{r}$ to drought were roughly the same with that of $P_{n}$. Irrigation after long-term drought made $T_{r}$ rapidly increase in a short-term and then reduced. However, irrigation after short-term drought could made $T_{r}$ recover to a normal level, verifying that the photosynthesis and transpiration ability of leaves had not been damaged after only a short-term drought during jointing period, while long-term drought caused them to be irreversibly affected [21,30]. After irrigation, $\mathrm{P}_{\mathrm{n}}$ could not show short-term compensatory recovery when maize suffered from long-term drought in tasseling period, which meant tasseling drought impacts were much severer than jointing drought impacts.

Besides, SFR is an important variable to represent transpiration rate in the plant scale [41]. The research on SFR is still relatively scant. The maximal SFR observed in control treatment is about $300 \mathrm{~g} \cdot \mathrm{h}^{-1}$ which is obviously larger than that in study from Wang et al. [42] for the differences of cropping system, variety and planting area and is approximate to that observed by $\mathrm{Yu}$ et al. [43]. Moreover, drought was capable of altering the exponential relationships between daily SFR and active photosynthetic radiation to linear ones, while after irrigation the exponential relationships could recover. The recovered exponential relationship was less significant after long-term jointing drought, compared with that after short-term jointing drought. The drought in tasseling period even eradicated the linear relationship, but the exponential relationship could still recover after irrigation.

In conclusion, a longer and later drought duration led to stronger impacts on maize in biomass production, yield reductions, leaf photosynthesis and plant transpiration rate, where the short-term jointing drought made slight impacts, which could recover after irrigation. Inversely, after long-term drought, the physiological functions and biomass production could not recover. 
Author Contributions: P.J. conceived, designed and performed the experiments and drafted this paper, T.-H.Z. and Z.-Q.Z. helped performed the field measurements, Y.M. and L.-Y.G. reviewed and edited this paper, F.C. conceived and designed the experimental scheme.

Funding: This paper is supported by the National Natural Science Foundation of China (Grant number: 41775110, 31701313), The Cultivation Plan for Youth Agricultural Science and Technology Innovative Talents of Liaoning Province (Grant number: 2015060), Research Fund for doctoral program of Liaoning meteorological bureau (Grant number: D201504), The Agricultural Tackle Key Problem and Achievements Industrialization Project of Science and Technology Department of Liaoning Province (Grant number: 2014210003).

Acknowledgments: Many thanks go to the valuable work of anonymous reviewers.

Conflicts of Interest: The authors declare no conflict of interest.

\section{Nomenclature}

$\begin{array}{ll}\mathrm{DM} & \text { dry matter } \\ \mathrm{DM}_{\text {entire plant }} & \text { dry matter of entire plant } \\ \mathrm{DM}_{\text {leaf }} & \text { dry matter of leaf } \\ \mathrm{DM}_{\text {stalk }} & \text { dry matter of stalk } \\ \mathrm{DM}_{\text {ear }} & \text { dry matter of ear } \\ \mathrm{DM}_{\text {root }} & \text { dry matter of root } \\ \mathrm{P}_{\mathrm{n}} & \text { Net photosynthetic rate } \\ \mathrm{DMPC} & \text { dry matter partitioning coefficient } \\ \mathrm{DMPC}_{\text {leaf }} & \text { dry matter partitioning coefficient of leaf } \\ \mathrm{DMPC}_{\text {stalk }} & \text { dry matter partitioning coefficient of stalk } \\ \mathrm{DMPC}_{\text {ear }} & \text { dry matter partitioning coefficient of ear } \\ \mathrm{DMPC}_{\text {root }} & \text { dry matter partitioning coefficient of root } \\ \mathrm{SFR} & \text { sap flow rate } \\ \mathrm{T}_{\mathrm{r}} & \text { transpiration rate }\end{array}$

\section{References}

1. Jaleel, C.A.; Manivannan, P.A.; Wahid, A.; Farooq, M.; Al-Juburi, H.J.; Somasundaram, R.A.; Panneerselvam, R. Drought stress in plants: A review on morphological characteristics and pigments composition. Int. J. Agric. Biol. 2009, 11, 100-105.

2. He, B.; Zhu, J. Constructing community gardens? Residents' attitude and behaviour towards edible landscapes in emerging urban communities of China. Urban For. Urban Green. 2018, 34, 154-165. [CrossRef]

3. Zhao, D.; Zhao, X.; Khongnawang, T.; Arshad, M.; Triantafilis, J. A Vis-NIR spectral library to predict clay in Australian cotton growing soil. Soil Sci. Soc. Am. J. 2018. [CrossRef]

4. He, B.J.; Zhao, D.X.; Zhu, J.; Darko, A.; Gou, Z.H. Promoting and implementing urban sustainability in China: An integration of sustainable initiatives at different urban scales. Habitat Int. 2018. [CrossRef]

5. Zhao, Z.Q.; He, B.J.; Li, L.G.; Wang, H.B.; Darko, A. Profile and concentric zonal analysis of relationships between land use/land cover and land surface temperature: Case study of Shenyang, China. Energy Build. 2017, 155, 282-295. [CrossRef]

6. Cheng, Z.; Meng, J.; Wang, Y. Improving spring maize yield estimation at field scale by assimilating time-series HJ-1 CCD data into the WOFOST model using a new method with fast algorithms. Remote Sens. 2016, 8, 303. [CrossRef]

7. Meng, Q.; Chen, X.; Lobell, D.B.; Cui, Z.; Zhang, Y.; Yang, H.; Zhang, F. Growing sensitivity of maize to water scarcity under climate change. Sci. Rep. 2016, 6, 19605. [CrossRef] [PubMed]

8. Ji, R.P.; Che, Y.S.; Zhu, Y.N.; Liang, T.; Feng, R.; Yu, W.Y.; Zhang, Y.S. Impacts of drought stress on the growth and development and grain yield of spring maize in Northeast China. Chin. J. Appl. Ecol. 2012, 23, 3021-3026. (In Chinese)

9. Bai, L.P.; Sui, F.G.; Ge, T.D.; Sun, Z.H.; Lu, Y.Y.; Zhou, G.S. Effect of soil drought stress on leaf water status, membrane permeability and enzymatic antioxidant system of maize. Pedosphere 2006, 16, 326-332. [CrossRef]

10. Ahuja, I.; de Vos, R.C.; Bones, A.M.; Hall, R.D. Plant molecular stress responses face climate change. Trends Plant Sci. 2010, 15, 664-674. [CrossRef] [PubMed] 
11. Xu, Z.; Zhou, G.; Shimizu, H. Plant responses to drought and rewatering. Plant Signal. Behav. 2010, 5, 649-654. [CrossRef] [PubMed]

12. Yang, J.; Sun, J.; Ge, Q.; Li, X. Assessing the impacts of urbanization-associated green space on urban land surface temperature: A case study of Dalian, China. Urban For. Urban Green. 2017, 22, 1-10. [CrossRef]

13. Ribaut, J.M.; Betran, J.; Monneveux, P.; Setter, T. Drought tolerance in maize. In Handbook of Maize: Its Biology; Springer: New York, NY, USA, 2009; pp. 311-344.

14. Lobell, D.B.; Roberts, M.J.; Schlenker, W.; Braun, N.; Little, B.B.; Rejesus, R.M.; Hammer, G.L. Greater sensitivity to drought accompanies maize yield increase in the US Midwest. Science 2014, 344, 516-519. [CrossRef] [PubMed]

15. Mou, B.; He, B.J.; Zhao, D.X.; Chau, K.W. Numerical simulation of the effects of building dimensional variation on wind pressure distribution. Eng. Appl. Comput. Fluid Mech. 2017, 11, 293-309. [CrossRef]

16. Avramova, V.; AbdElgawad, H.; Zhang, Z.; Fotschki, B.; Casadevall, R.; Vergauwen, L.; Knapen, D.; Taleisnik, E.; Guisez, Y.; Asard, H.; et al. Drought induces distinct growth response, protection, and recovery mechanisms in the maize leaf growth zone. Plant Physiol. 2015, 169, 1382-1396. [CrossRef] [PubMed]

17. Meyer, E.; Aspinwall, M.J.; Lowry, D.B.; Palacio-Mejía, J.D.; Logan, T.L.; Fay, P.A.; Juenger, T.E. Integrating transcriptional, metabolomic, and physiological responses to drought stress and recovery in switchgrass (Panicum virgatum L.). BMC Genom. 2014, 15, 527. [CrossRef] [PubMed]

18. Harrison, M.T.; Tardieu, F.; Dong, Z.; Messina, C.D.; Hammer, G.L. Characterizing drought stress and trait influence on maize yield under current and future conditions. Glob. Chang. Biol. 2014, 20, 867-878. [CrossRef] [PubMed]

19. Abid, M.; Tian, Z.; Ata-Ul-Karim, S.T.; Wang, F.; Liu, Y.; Zahoor, R.; Jiang, D.; Dai, T. Adaptation to and recovery from drought stress at vegetative stages in wheat (Triticum aestivum) cultivars. Funct. Plant Biol. 2016, 43, 1159-1169. [CrossRef]

20. Hacke, U.G.; Jacobsen, A.L.; Brandon Pratt, R.; Maurel, C.; Lachenbruch, B.; Zwiazek, J. New research on plant-water relations examines the molecular, structural, and physiological mechanisms of plant responses to their environment. New Phytol. 2012, 196, 345-348. [CrossRef] [PubMed]

21. Lawlor, D.W.; Tezara, W. Causes of decreased photosynthetic rate and metabolic capacity in water-deficient leaf cells: A critical evaluation of mechanisms and integration of processes. Ann. Bot. 2009, 103, 561-579. [CrossRef] [PubMed]

22. Nielsen, D.C.; Vigil, M.F.; Benjamin, J.G. The variable response of dryland corn yield to soil water content at planting. Agric. Water Manag. 2009, 96, 330-336. [CrossRef]

23. Efeoğlu, B.; Ekmekci, Y.; Cicek, N. Physiological responses of three maize cultivars to drought stress and recovery. S. Afr. J. Bot. 2009, 75, 34-42. [CrossRef]

24. Djaman, K.; Irmak, S.; Rathje, W.R.; Martin, D.L.; Eisenhauer, D.E. Maize evapotranspiration, yield production functions, biomass, grain yield, harvest index, and yield response factors under full and limited irrigation. Trans. ASABE 2013, 56, 373-393. [CrossRef]

25. Song, H.; Li, Y.; Zhou, L.; Xu, Z.; Zhou, G. Maize leaf functional responses to drought episode and rewatering. Agric. For. Meteorol. 2018, 249, 57-70. [CrossRef]

26. Mi, N.; Cai, F.; Zhang, Y.; Ji, R.; Zhang, S.; Wang, Y. Differential responses of maize yield to drought at vegetative and reproductive stages. Plant Soil Environ. 2018, 64, 260-267.

27. SPSS Inc. SPSS®13.0 Base User's Guide; SPSS Inc.: Chicago, IL, USA, 2004.

28. Qu, J.L.; Zhao, D.X. Comparative research on tillable properties of diatomite-improved soils in the Yangtze River Delta region, China. Sci. Total Environ. 2016, 568, 480-488. [CrossRef] [PubMed]

29. Daryanto, S.; Wang, L.; Jacinthe, P.A. Global synthesis of drought effects on maize and wheat production. PLoS ONE 2016, 11, e0156362. [CrossRef] [PubMed]

30. Han, X.Y.; Song, F.B. Effect of drought stress on root growth and rhizosphere nutrients of maize (Zea mays L.). J. Soil Water Conserv. 2006, 20, 170-172.

31. Bonato, O.; Schulthess, F.; Baumgärtner, J. Simulation model for maize crop growth based on acquisition and allocation processes for carbohydrate and nitrogen. Ecol. Model. 1999, 124, 11-28. [CrossRef]

32. Anjum, S.A.; Xie, X.Y.; Wang, L.C.; Saleem, M.F.; Man, C.; Lei, W. Morphological, physiological and biochemical responses of plants to drought stress. Afr. J. Agric. Res. 2011, 6, 2026-2032. 
33. Mi, N.; Cai, F.; Zhang, Y.S.; Ji, R.P.; Yu, W.Y.; Zhang, S.J.; Fang, Y. Effect of continuous drought during different growth stages on maize and its quantitative relationship with yield loss. Chin. J. Appl. Ecol. 2017, 28, 1563-1570. (In Chinese)

34. Gibson, L.R.; Paulsen, G.M. Yield components of wheat grown under high temperature stress during reproductive growth. Crop Sci. 1999, 39, 1841-1846. [CrossRef]

35. Kamara, A.Y.; Menkir, A.; Badu-Apraku, B.; Ibikunle, O. The influence of drought stress on growth, yield and yield components of selected maize genotypes. J. Agric. Sci. 2003, 141, 43-50. [CrossRef]

36. Anjum, S.A.; Wang, L.C.; Farooq, M.; Hussain, M.; Xue, L.L.; Zou, C.M. Brassinolide application improves the drought tolerance in maize through modulation of enzymatic antioxidants and leaf gas exchange. J. Agron. Crop Sci. 2011, 197, 177-185. [CrossRef]

37. Rucker, K.S.; Kvien, C.K.; Holbrook, C.C.; Hook, J.E. Identification of peanut genotypes with improved drought avoidance traits. Peanut Sci. 1995, 22, 14-18. [CrossRef]

38. Aroca, R.; Irigoyen, J.J.; Sánchez-Díaz, M. Drought enhances maize chilling tolerance. II. Photosynthetic traits and protective mechanisms against oxidative stress. Physiol. Plant. 2003, 117, 540-549. [CrossRef] [PubMed]

39. Yu, W.Y.; Ji, R.P.; Feng, R.; Wu, J.W.; Zhang, Y.S. Effect of drought stress in jointing stage on the photosynthetic light response of spring maize in Northeast China. In IOP Conference Series: Materials Science and Engineering; IOP Publishing: Bristol, UK, 2018; Volume 392, p. 042032.

40. Acevedo, E.; Hsiao, T.C.; Henderson, D.W. Immediate and subsequent growth responses of maize leaves to changes in water status. Plant Physiol. 1971, 48, 631-636. [CrossRef] [PubMed]

41. Jiang, X.; Kang, S.; Li, F.; Du, T.; Tong, L.; Comas, L. Evapotranspiration partitioning and variation of sap flow in female and male parents of maize for hybrid seed production in arid region. Agric. Water Manag. 2016, 176, 132-141. [CrossRef]

42. Wang, S.Q.; Zhang, S.Q.; Wang, X.L. Transpiration of maize under different cultivation patterns in the Loess Tableland. Chin. J. Eco-Agric. 2013, 21, 432-439. [CrossRef]

43. Yu, W.Y.; Ji, R.P.; Feng, R.; Wu, J.W.; Zhang, Y.S.; Wang, P.; Wang, T. Effects of different drought stresses and re-watering on sap flow dynamic of spring maize Danyu 39. Agric. Res. Arid Areas 2016, 34, 163-170. 